\title{
Effect of gender on hospital admissions for asthma and prevalence of self-reported asthma: a prospective study based on a sample of the general population
}

Eva Prescott, Peter Lange, Jørgen Vestbo, and The Copenhagen City Heart Study Group

\begin{abstract}
Background - Women are more often admitted to hospital for asthma than men. A study was undertaken to determine whether this is caused by gender differences in the prevalence or severity of the disease.

Methods - Admissions to hospital for asthma in 13540 subjects were followed from 1977 to 1993.

Results - At baseline 315 subjects (2.3\%) reported asthma, $2.2 \%$ of women and $2.5 \%$ of men. During follow up 160 subjects were admitted to hospital for asthma. After controlling for self-reported asthma and smoking, women had a higher risk of being admitted to hospital than men (relative risk $1.7,95 \%$ confidence interval 1.2 to 2.4). This increased risk was not due to misclassification of chronic obstructive pulmonary disease (COPD) as asthma.

Conclusions - These findings indicate gender-related differences in either the severity, perception, or management of asthma.

(Thorax 1997;52:287-289)
\end{abstract}

Keywords: longitudinal population study, women, asthma morbidity.

Most studies report a female preponderance in the use of health care in asthma (medication, clinical practice, and admission to hospital). ${ }^{1-3}$ It is not clear if this is caused by differences in prevalence, severity, or management of the disease. We have studied the prevalence of selfreported asthma and admission to hospital due to asthma in relation to gender by linking data from the prospective population based Copenhagen City Heart Study with the National Hospital Discharge Register.

\section{Methods}

The study was based on data from The Copenhagen City Heart Study, a prospective epidemiological cardiopulmonary study initiated in 1976. After age stratification, 19698 subjects aged 20 years or over were randomly sampled from an area in Copenhagen of which 14223 (response rate $72 \%$ ) attended an examination in 1976-8. Details of the study, including calculation of predicted values of forced expiratory volume in one second $\left(\mathrm{FEV}_{1}\right)$ based on spirometric data on healthy never smokers, have been presented previously. ${ }^{4}$

Self-reported asthma was defined as answering "yes" to the question: "Do you have asthma?" Tobacco characteristics included smoking status - that is, never smoker, exsmoker, light smoker (1-14 g tobacco/day), and heavy smoker ( $\geq 15 \mathrm{~g}$ tobacco/day), years of smoking for present and ex-smokers, and degree of inhalation for present smokers.

All subjects were followed using the National Hospital Discharge Register. Loss to follow up was caused only by emigration $(<0.5 \%)$. Subjects were followed until 31 December 1992 for admissions with asthma as the main diagnosis (ICD-8 493).

The risk of hospital admission was analysed using Cox's proportional hazards model with time from enrolment as the underlying timescale. The outcome of interest was the first admission to hospital or death from asthma if this was not preceded by admission to hospital. Men and women were analysed in the same models. To verify the assumption that any difference between the two sexes could be described with one gender parameter, first order interaction terms of the gender parameter and all other covariates in the model were tested separately.

\section{Results}

The study sample consisted of 7436 women and 6104 men after exclusion of non-responders on self-reported asthma $(n=683)$. Men were more likely than women to be heavy smokers and to have been smoking longer, whereas women were more likely to live alone. Three hundred and fifteen subjects $(2.3 \%)$ reported asthma, 163 women $(2.2 \%)$ and 152 men $(2.5 \%)$ 
Table 1 Risk of admission to hospital or death from asthma analysed by Cox's regression model ( $n=13540,170$ events)

\begin{tabular}{|c|c|c|c|c|}
\hline & Model 1 & Model 2 & Model 3 & Final model \\
\hline \multicolumn{5}{|l|}{ Gender: } \\
\hline Men & 1 & 1 & 1 & 1 \\
\hline Women & $1.3(0.9$ to 1.7$)$ & $1.4(1.0$ to 1.9$)$ & $1.7(1.2$ to 2.4$)$ & $1.7(1.2$ to 2.4$)$ \\
\hline \multicolumn{5}{|l|}{ Smoking status: } \\
\hline Never smoker & 1 & - & 1 & 2 \\
\hline Ex-smoker & $1.6(0.9$ to 2.7$)$ & & $1.0(0.5 \text { to } 2.0)^{1}$ & \\
\hline Non-inhaler & $1.0(0.6$ to 1.9$)$ & & $1.2(0.7$ to 2.2$)$ & \\
\hline Light smoker $(<15 \mathrm{~g} /$ day $)$ & $1.9(1.1$ to 3.2$)$ & & $0.8(0.4 \text { to } 1.9)^{1}$ & \\
\hline Heavy smoker $(\geq 15 \mathrm{~g} /$ day & $2.3(1.4$ to 3.8$)$ & & $1.0(0.5 \text { to } 2.3)^{1}$ & \\
\hline Years of smoking ${ }^{3}$ (per 10 years) & $1.2(1.1$ to 1.3$)$ & & $1.3(1.1$ to 1.6$)$ & $1.2(1.1$ to 1.4$)$ \\
\hline \multicolumn{5}{|l|}{ Self-reported asthma: } \\
\hline No & 1 & 1 & - & 1 \\
\hline Yes & $31.1(22.8$ to 42.4$)$ & $31.6(23.2$ to 43.1$)$ & & $29.9(21.9$ to 40.8$)$ \\
\hline
\end{tabular}

One hundred and sixty (1.2\%) subjects, 100 of whom were women, were admitted to hospital at least once during follow up with a main diagnosis of asthma. Eighteen subjects (11 women) died from asthma, 10 of whom had not previously been admitted to hospital for asthma. Table 1 shows the results of the Cox regression analyses for hospital admissions/ death caused by asthma. In the final model the risk of hospital admission was significantly increased in women with a relative risk (RR) of 1.7 (95\% CI 1.2 to 2.4 ).

To try to eliminate diagnostic bias by gender - that is, admission to hospital for chronic obstructive pulmonary disease (COPD) more likely to be misclassified as asthma in women than in men - analyses were repeated on restricted subpopulations chosen to exclude as many subjects with misclassified COPD as possible. The analyses were first repeated on subjects with $\mathrm{FEV}_{1}$ above $80 \%$ predicted $(\mathrm{n}=$ 8582,47 events). Adjusting for smoking, selfreported asthma and age, the RR in women was 2.5 (95\% CI 1.3 to 5.0$)$. When analyses were repeated on younger subjects (follow up truncated at age $60, \mathrm{n}=10125,59$ events) the $\mathrm{RR}$ in women was 2.6 (95\% CI 1.4 to 4.8$)$. In a separate analysis of all never smokers $(\mathrm{n}=$ 2783, 24 events) there was no gender difference (RR 1.0; 95\% CI 0.4 to 2.6 ), but among never smokers aged less than $60(\mathrm{n}=1941,10$ events $)$ the RR in women was 4.3 (95\% CI 0.4 to 35 ).

There was no interaction between gender and self-reported asthma. Cohabitation, marital status, level of education, and household income did not significantly predict hospital admissions. When the 683 non-responders on self-reported asthma were included in the analyses of hospital admissions the RR for gender was unaffected.

\section{Discussion}

This is the first study of hospital admission rates for asthma which is adjusted for the underlying prevalence of self-reported asthma and smoking. Women had an approximately $70 \%$ higher risk of being admitted to hospital than men.
Self-reported asthma is often used in epidemiological settings and has been validated in relation to both bronchial hyperreactivity and a clinical diagnosis of asthma. ${ }^{5}$ The prevalence of self-reported asthma was $2.3 \%$, which is similar to or lower than other studies. The differences may be due in part to the definitions of asthma used. We found no gender difference in the crude prevalence of asthma. Reports from other studies differ on this point but most, like ours, have found no gender difference.

Our results on gender differences in hospital admission rates are in agreement with others. A study in England and Wales found agespecific hospital admission rates for asthma in adults to be consistently higher in women than in men. ${ }^{2}$ In a study from Pennsylvania women were admitted to hospital for asthma 2.5-3 times more often than men, ${ }^{1}$ and in another study from the USA elderly women had higher rates of admission for asthma whereas admissions for all other respiratory diseases were higher in men. ${ }^{3}$ None of these studies adjusted for the underlying prevalence of asthma or for smoking.

The possibility that this gender difference reflects generally lower admission thresholds for women must be considered. However, this is not the case for pneumonia in our own study population (unpublished observations) or for other respiratory diseases. ${ }^{3}$ In addition, women with asthma have been reported to experience longer hospital stays per admission, ${ }^{1}$ indicating perhaps that adult women are more severely affected by asthma than men, and a British case-control study of asthmatic patients has shown both all-cause and respiratory mortality to be particularly raised in women with asthma. $^{6}$

Another cause for the observed disparities in asthma admission rates between men and women could be different management of the disease. Clinical studies have indicated that women may have inadequate inhaler technique, and physicians may be reluctant to prescribe steroids to women because of the possibility of pregnancy or concern for potential bone demineralisation. 
In conclusion, these data show that, although there is no gender difference in the prevalence of asthma, women have a considerably higher risk than men of being admitted to hospital for the disease. This raises the possibility of genderrelated differences in the severity of asthma or, perhaps, in the management of the disease, including admission thresholds.

The following are members of The Copenhagen City Heart Study Group: G Jensen, P Schnohr, M Appleyard, J Nyboe, M Grenbæk, B Nordestgaard, P Lange. This study was supported by The National Union against Lung Diseases, The Danish Heart Foundation, and The Danish Medical Research Council (12-1661-1).
1 Skobeloff EM, Spivey WH, Clair SS, Schoffstall JM. The influence of age and sex on asthma admissions. $\mathscr{f} A M A$ 1992;268:3437-40.

2 Hyndman SJ, Williams DR, Merrill SL, Lipscombe JM, Palmer CR. Rates of admission to hospital for asthma (see comments). BMF 1994;308:1596-600.

3 Morris RD, Munasinghe RL. Geographic variability in hospital admission rates for respiratory disease among the elderly in the United States. Chest 1994;106:1172-81.

4 Lange $P$, Nyboe J, Appleyard M, Jensen G, Schnohr P. Ventilatory function and chronic mucus hypersecretion as predictors of death from lung cancer. Am Rev Respir Dis predictors of death

5 Enarson DA, Vedal S, Schulzer M, Dybuncio A, Chan-Yeung $M$. Asthma, asthmalike symptoms, chronic bronchitis, and the degree of bronchial hyperresponsiveness in epidemiologic surveys. Am Rev Respir Dis 1987;136:613-7.

6 Markowe HL, Bulpitt CJ, Shipley MJ, Rose G, Crombie DI Fleming DM. Prognosis in adult asthma: a national study. BMF 1987;295:949-52.

\section{Occult lung cancer in patients with bullous emphysema}

\author{
Federico Venuta, Erino A Rendina, Edoardo O Pescarmona, Tiziano De Giacomo, \\ Dario Vizza, Isac Flaishman, Costante Ricci
}

Department of Thoracic Surgery

F Venuta

E A Rendina

T De Giacomo

D Vizza

I Flaishman

C Ricci

Department of Experimental

Medicine and

Pathology

E O Pescarmona

University di Roma

"La Sapienza",

Policlinico Umberto I,

Viale del Policlinico,

00100 Rome, Italy

Correspondence to:

Dr F Venuta.

Received 2 February 1996 Returned to authors

23 April 1996

Revised version received

10 July 1996

Accepted for publication

25 September 1996

\begin{abstract}
Background - The incidence of lung cancer is increased in patients with bullous emphysema.

Methods - A series of 95 patients undergoing excision of bullous lung tissue was reviewed to determine the incidence and long term outcome of occult carcinoma present in the resected material.

Results - Four patients $(4.2 \%)$ had peripheral foci of large cell carcinoma in the resection specimen (three bullectomies and one lobectomy).

Conclusions - Resected bullous lung tissue should be carefully examined for areas of bronchogenic carcinoma. The results of incidental complete excision are favourable.
\end{abstract}

(Thorax 1997;52:289-290)

Keywords: bullous emphysema, lung cancer.

Early diagnosis and complete resection are considered key factors in achieving long term survival in non-small cell lung cancer. The incidence of this malignancy is reported to be 32 times higher in patients with bullous emphysema. ${ }^{1-3}$ These patients may, however, also require surgery for excision of bullous air spaces because of functional impairment or other complications. Since scar carcinoma has been reported, ${ }^{4-6}$ we routinely perform complete gross and histological examination of the wall of the resected bulla, with multiple samples of scars, areas of increased thickness, and grossly normal bulla wall.

We report our experience with four patients who underwent surgery for giant bullous em- physema with an incidental finding of microscopic occult lung cancer localised in a macroscopically normal section of the wall of the bulla.

\section{Methods}

From 1979 to 199395 patients with bullous emphysema of the lung underwent surgical bullectomy. Four $(4.2 \%)$ of these patients (aged $40,44,48$, and 51 years) were found on routine histological examination of the resected material to have occult carcinoma and are the subject of this retrospective study. Normal phenotypes for $\alpha_{1}$-antitrypsin were found. Chest radiography and computed tomographic (CT) scanning were diagnostic for giant bullous disease with enlarged air spaces accounting for at least $50 \%$ of the involved hemithorax. No increased pleural thickness, lung nodules, or other solid lesions were evident at preoperative evaluation. Pulmonary function tests showed a mean forced expiratory volume in one second $\left(\mathrm{FEV}_{1}\right)$ of 1.321 , a mean functional residual capacity (FRC) of $5.51 \mathrm{l}$, and a mean $\mathrm{PaO}_{2}$ of $9.0 \mathrm{kPa}$; the mean MVV was $32 \%$ of predicted. Pulmonary perfusion and ventilation scans were consistent with the presence of poorly ventilated unperfused air spaces. Angiography revealed that the pulmonary vessels of the residual lung were dislocated and compressed by the bulla with no sign of anomalous vascular proliferation. Fibreoptic bronchoscopy did not show any endobronchial lesion. Three bullectomies and one lobectomy were performed through a standard posterolateral thoracotomy as these cases predated the advent of videoassisted thoracoscopy. The pathologist sampled 
every area of increased thickness or scar either at the base or on the wall of the bulla, in addition to random multiple sampling of several apparently normal areas. After the histological diagnosis of cancer was obtained the four patients were staged with total body CT scanning and a bone scan.

\section{Results}

No postoperative complications were observed. Postoperative pulmonary function tests showed increased values with a mean $\mathrm{FEV}_{1}$ of 1.81 , a mean FRC of 4.21 , a mean MVV of $66 \%$ of predicted; mean $\mathrm{PaO}_{2}$ increased to $11.09 \mathrm{kPa}$. Macroscopically, the surface of the bullae was smooth in all cases without any pleural retraction and no sign of suspicious lesions. All scars and areas of increased thickness of the wall were histologically classified as fibrosis. Microscopic foci of lung carcinoma were obtained in areas without any significant macroscopic alteration or scars. The lesions were composed of large atypical cells with prominent nucleoli and abundant clear cytoplasm.

Postoperative staging did not show the presence of lymph node involvement or distant metastases and the patients were classified as T1N0M0. The patients are alive and free of disease after 10, eight, seven, and five years, respectively.

\section{Discussion}

The increased incidence of lung cancer in patients with bullous emphysema may pose several problems regarding the timing and strategy of surgery. There are many reports in the literature regarding radiologically evident bronchogenic carcinoma presenting simultaneously with bullae or years after their surgical resection, ${ }^{1-37-10}$ but we have found no other report concerning the detection of occult lung cancer associated with giant bullous emphysema. The presence of scars, the smoking habit of the patients, and air trapping within the bulla may contribute to the development of cancer if the enlarged air space is not removed. ${ }^{4-6}$ Accurate preoperative imaging is necessary to detect any dubious area on the wall of the bulla or in the residual lung. Nevertheless, microscopic lesions can be detected only at pathological examination and even frozen sections may not be of help. In fact, in all our cases the foci of neoplastic cells were detected "by chance" on random biopsy specimens of macroscopically normal areas of the wall of the bulla. The lesions were some distance from the scars and thus we did not classify them as "scar carcinoma".

Any lung mass associated with bullae should be considered an indication for surgery. On the other hand, patients with giant bullous disease detected radiologically, without evidence of parenchymal lesions, require different considerations. These patients undergo surgery on the basis of the dimensions of the bulla, the degree of functional impairment, and the presence of complications.

For these reasons, a bulla should be completely excised rather than plicated or folded at its base to reinforce the suture line as has been proposed by others. ${ }^{11}$ Similarly, the Monaldi procedure and its modifications ${ }^{12}$ should be considered only in patients unfit for surgery. In all our patients the tumour was far away from the stapler line and thus the resection could be considered complete.

On the basis of our limited experience we believe that the incidence of occult lung cancer in this subset of patients may be underestimated. Surgical resection of emphysematous bullae should be as complete as possible and accurate histological examination of all resected material should be undertaken.

1 Stoloff IL, Kanofsky P, Magliner L. The risk of lung cance in males with bullous disease of the lung. Arch Environ

2 Scannell JG. "Bleb" carcinoma of the lung. F Thorac Cardiovasc Surg 1980;80:904-8.

3 Goldstein MJ, Snider GL, Liberson M, Poske RM. Bronchogenic carcinoma and giant bullous disease. Am Rev chogenic carcinoma and giant

4 Yokoo H, Suckow EE. Peripheral lung cancers arising in scars. Cancer 1961;14:1205-15.

5 Raeburn C, Spencer H. Lung scar cancers, Br $\mathcal{7}$ Tuber 1957;51:237-45.

6 Freant LJ, Joseph WL, Adkins PC. Scar carcinoma of the lung, fact or fantasy. Ann Thorac Surg 1974;17:531-7.

7 Johnson KT. Severe bullous emphysema and contralatera bronchogenic carcinoma: successful management with staged bilateral thoracotomy. Wis Med f 1985;84:11-14.

8 Nickoladze GD. Bullae and lung cancer. $\mathcal{F}$ Thorac Cardiovas Surg 1993;105:186.

9 Guerin JC, Martinat Y, Boniface E, Champel F. Distrophie bulleuse et cancers bronchopulmonaires chez des sujets jeunes. Rev Pneumol Clin 1986;42:21-5.

10 Aronberg DJ, Sagel SS, Le Frank S, Kuhn C, Susman N. Lung carcinoma associated with bullous lung disease in young men. $A \not R$ 1980;134:249-52.

11 Deslauriers J, Leblanc P. Bullous and bleb diseases of the lung. In: Shields TW, ed. General thoracic surgery 4th edn. Malvern, Pennsylvania: Williams and Wilkins, 1994 907-29.

12 Shah SS, Goldstraw P. Surgical treatment of bullous emphysema: experience with the Brompton technique. Ann Thorac Surg 1994;58:1452-6. 